\title{
Studies on Damage Properties of MgO-C Refractories through Hertzian Indentation at Room and High Temperatures
}

\author{
Geun-Ho Cho*, Yunki Byeun**, and Yeon-Gil Jung $(\mathbb{D} * \dagger$ \\ *School of Materials and Engineering, Changwon National University, Changwon 51440, Korea \\ **Technical Research Laboratories, POSCO, Pohang 37859, Korea
}

(Received November 7, 2018; Revised December 31, 2018; Accepted January 7, 2019)

\begin{abstract}
$\mathrm{MgO}-\mathrm{C}$ refractories are used in basic furnaces and steel ladles due to their many desirable properties, such as excellent thermal shock resistance via low thermal expansion, and high thermal conductivity. However, the mechanical and thermal properties of the refractory continuously deteriorate by spalling phenomena and pore generation due to the oxidation of graphite, used as a carbon source, indicating that the characteristics and performance of $\mathrm{MgO}-\mathrm{C}$ refractories need to be improved by using a new material or composition. In this study, the use of a Hertzian indentation test as a method for determining the damage and fracture behavior of an $\mathrm{MgO}-\mathrm{C}$ refractory is described. The results highlight that Hertzain indentation tests can be one of the important evaluation tools for quasi-plastic damage accumulation of $\mathrm{MgO}-\mathrm{C}$ refractories during falling process of scrap metal.
\end{abstract}

Key words : Hertzian indentation, MgO-C Refractory, Damage behavior, Fracture behavior, Mechanical property

\section{Introduction}

$\mathrm{G}$ enerally, magnesia $(\mathrm{MgO})$ in the form of magnesia-carTbon (MgO-C) is the most important refractory material for the steelmaking process. The material has an appropriate melting point and abrasion resistance while the carbon distributed in the matrix between the $\mathrm{MgO}$ aggregates elevates the thermal conductivity of refractories, and improves the spalling resistance and corrosion resistance of slags. ${ }^{1)}$ The amount being used in making the molten pig-iron in blast furnaces recently is declining. Meanwhile, the number of processes that use large amounts of scrap is increasing, due to environmentally friendly considerations such as $\mathrm{CO}_{2}$ reduction. As a result, the life expectancy of $\mathrm{MgO}-\mathrm{C}$ refractories used in converters is decreasing due to damage from scrap drop impacts. ${ }^{2)}$ This is a major factor affecting steelmaking productivity and production costs. In order to prevent damage to $\mathrm{MgO}-\mathrm{C}$ refractories, efforts are being made to improve their strength, and the carbon content of $20 \%$ and higher in conventional $\mathrm{MgO}-\mathrm{C}$ refractories is being reduced to about $10 \%$ and lower. ${ }^{3)}$

Reducing the carbon content in $\mathrm{MgO}-\mathrm{C}$ refractories results in a decrease in refractory thermal conductivity, increase of the modulus of elasticity, and a reduction in resistance to spalling degradation from thermal shock. To avoid these issues, various studies have been carried out to improve

\footnotetext{
Corresponding author: Yeon-Gil Jung

E-mail : jungyg@changwon.ac.kr

Tel : +82-55-213-3712 Fax : +82-55-262-6486

ORCID

http://orcid.org/0000-0002-0416-2395
}

strength and spalling resistance within refractories using expanded graphite, carbon nanoparticles, or CNT. ${ }^{4-6)}$ A previous study focused on evaluating the mechanical properties of the improved refractory by comparing compressive and bending strengths (3-point bending test), but an appropriate evaluation of $\mathrm{MgO}-\mathrm{C}$ refractory impact damage caused by massive metal scrap drops in the converter was not conducted, and the experimental approach to determining the causal mechanism was limited. ${ }^{7-9)}$

Therefore, in this study, the Hertzian indentation test was applied as an evaluation method to quantify the impacts on the refractory, to investigate their effect on refractory damage. The material properties were determined by evaluating mechanical and damage durability. Since the 1980s, spherical indentation has been used to evaluate the damage resistance of ceramics. In this approach, irreversible deformation in a ceramic is caused by contact with or impact of a spherical ball, and the damage region contains microcracks by dislocation which are generally found in metals. ${ }^{10,11)}$ Thus, the Hertzian indentation test supplements the evaluation of mechanical properties using conventionally applied tensile, torsion, bending strength, and compression tests in order to assess the deformation and failure characteristics of ceramics. $^{12)}$

In addition, while the conventional sharp indentation method applies a load to analyze the material properties through plastic deformation, the Hertzian indentation test uses a spherical indenter to contact the test specimen, and investigates the damage, including the displacement and mechanical behavior, based on the indentation load..$^{10,13,14)}$

In this study, the effect of carbon content and antioxidant type and content on indentation load-displacement behavior 
was evaluated and investigated. In particular, the size and speed of the indentation were controlled to assess damage durability, taking into consideration the scrap curvature radius and impact velocity. Based on the room temperature experiment results, experimentation was then carried out at $1500^{\circ} \mathrm{C}$, which is the actual temperature at which $\mathrm{MgO}-\mathrm{C}$ refractories operate, and indentation testing applicable to high temperatures was conducted.

\section{Experimental Procedure}

\subsection{Starting Material and Test Specimen Fabrica- tion}

Table 1 shows the composition of the refractory used in the experimentation. The composition shown in Table 1 used commercial refractory raw materials. The main constituents were $\mathrm{MgO}$ (98\% purity, white fused $\mathrm{MgO}$, POSCO Chemtech) and carbon (graphite, 98\% purity, POSCO Chemtech) while a metallic antioxidant (metallic $\mathrm{Al}, \mathrm{Si}$, POSCO Chemtech) was mixed in at $4-9 \mathrm{wt} \%$ of the total mass, to prevent the oxidation of carbon. Alumina (fused $\mathrm{Al}_{2} \mathrm{O}_{3}$ powder, $<74 \mu \mathrm{m}, 98 \%$, POSCO Chemtech) was mixed with the metallic antioxidant within $2 \mathrm{wt} \%$ of the total mass ratio, to control the explosive properties of the metallic antioxidant and improve oxidation resistance at high temperatures.

For the metallic antioxidant, samples that only used $\mathrm{Al}$, and samples that used $\mathrm{Al} / \mathrm{Si}$ together, were fabricated. The carbon content and antioxidant type and content were varied, and roll milling was conducted by mixing liquid phenol resin binder to obtain a uniform mixture. The mixture was then cured for $24 \mathrm{~h}$ at $80^{\circ} \mathrm{C}$ followed by uniaxial pressing to fabricate the samples. Lastly, the samples were dried at $120^{\circ} \mathrm{C}$ to prepare the test specimens. For the experiments, all the specimens were dry cut and polished to prevent defects from hydration.

\subsection{Property Evaluation}

In order to evaluate the properties of the $\mathrm{MgO}-\mathrm{C}$ refractories, and compare the conventional bending strength method with the Hertzian indentation method, the test specimens were processed to be the same dimensions of $20 \times 20 \times 80$ $\mathrm{mm}$. For the bending strength test, a maximum pressure of

Table 1. Basic Formulations for Refractory Samples Prepared with Various Components

\begin{tabular}{ccccc}
\hline Sample & $\begin{array}{c}\text { Aggregate } \\
(\text { wt \%) }\end{array}$ & $\begin{array}{c}\text { Carbon } \\
\text { (wt \%) }\end{array}$ & \multicolumn{2}{c}{$\begin{array}{c}\text { Antioxidant } \\
\text { (wt \%) }\end{array}$} \\
\hline $\mathrm{A}-1$ & & $5 \%$ & $5 \%$ \\
$\mathrm{~A}-2$ & & $5 \%$ & $\mathrm{Al} / \mathrm{Al}_{2} \mathrm{O}_{3}$ & $8 \%$ \\
$\mathrm{~A}-3$ & $\mathrm{MgO}$ & $3 \%$ & & $9 \%$ \\
\cline { 3 - 5 } $\mathrm{B}-1$ & & $5 \%$ & & $5 \%$ \\
$\mathrm{~B}-2$ & & $17 \%$ & $\mathrm{Al}^{2} \mathrm{Si}$ & $4 \%$ \\
$\mathrm{~B}-3$ & & $14 \%$ & $\mathrm{Al}_{2} \mathrm{O}_{3}$ & $4 \%$ \\
\hline
\end{tabular}

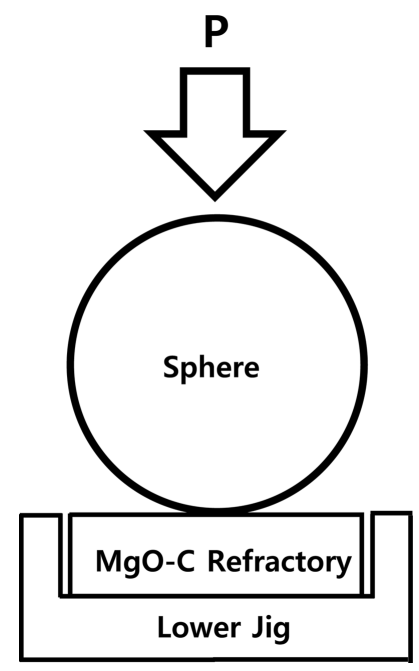

Fig. 1. Schematic diagram of Hertzian indentation test.

5 tons was possible, and measurements were carried out at $1500^{\circ} \mathrm{C}$ under an $\mathrm{Ar}(99.9 \%)$ atmosphere in a vacuum chamber. The 3-point bending strength was assessed with a crosshead speed of $0.2 \mathrm{~mm} / \mathrm{min}$ at a span distance of $60 \mathrm{~mm}$, and at least 5 measurements were performed for each specimen composition.

For the Hertzian indentation, the same hot bending strength test equipment mentioned earlier was used. For the indentation at high temperatures of $1500^{\circ} \mathrm{C}$ and higher, the indenter was a spherical ball of 2.20-6.36 mm made of carbon (graphite). The $\mathrm{MgO}-\mathrm{C}$ refractory specimen was coated with gold for convenient observation of the indentation size (contact area), and the speed of indentation was varied from $0.2-0.5 \mathrm{~mm} / \mathrm{min}$, as shown in Fig. 1 . After the indentation testing, the damage was observed using an optical microscope and the indentation load-deformation behavior was measured according to the indenter size, load, and indentation speed. Also, the residual and maximum stresses were measured through the damage range caused by the contact between the indenter and test specimen at room and high temperatures, in order to investigate the impact of the indentation temperature. ${ }^{15,16)}$

\section{Results and Discussion}

\subsection{Hertzian Indentation Test}

Figure 2 shows diagrams illustrating the indentation load-deformation behavior and cracking behavior that occurred in the Hertzian indentation testing. Damage and fractures formed in the following order. (a) The surface responded linearly to the indentation and since the response of the refractory being indented was elastic, the specimen recovered to its original form once the load was removed. (b) A ring fracture was formed outside the spherical indenter area due to the increased compression produced by the indentation, and deformation occurred because the specimen did not recover to its original form when the load was 


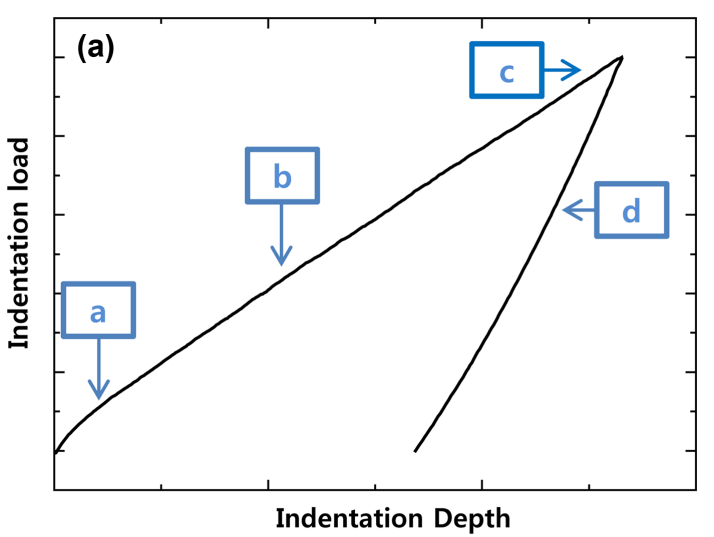

(b)

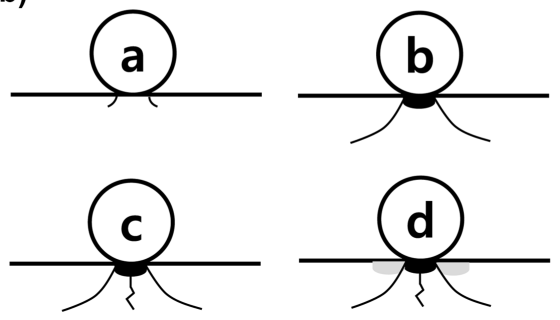

Fig. 2. Contact damage mechanisms in Hertzian indentation test: (a) Indentation curve and (b) Crack formation behavior.

removed. (c) When the compression was further increased, crack formation increased due to the effect of the loading. (d) When the load was removed, the cracks closed, and the cracks propagated in the refractory as in a quasi-plastic domain. When stress was continuously applied, the material was damaged, and it was observed that deformation remained after the stress was removed, as the specimen did not recover back to its original form. ${ }^{17}$

\subsection{Indentation Characteristics According to the Carbon and Antioxidant Content and Composition}

In order to investigate the effect of the carbon content on the indentation load-displacement behavior of the $\mathrm{MgO}-\mathrm{C}$ refractory, the displacement in specimens with varying carbon content (A and B type specimens in Table 1) was measured according to the indentation load, and the results are shown in Fig. 3. The deformation of the A-3 specimen, which had the lowest carbon content among the A type specimens, was found to be the smallest. Meanwhile, the difference in the deformations of the A-1 and A-2 specimens with the same carbon content was determined to be a result of the effect of the antioxidant and other additives in addition to carbon.

The B type specimens had higher carbon content than the A type specimens and the large difference in the carbon content between the specimen types was thought to result in the large differences in deformation. The contact areas on the surface of the specimens were measured with different carbon contents (B type specimens) for a contact load of
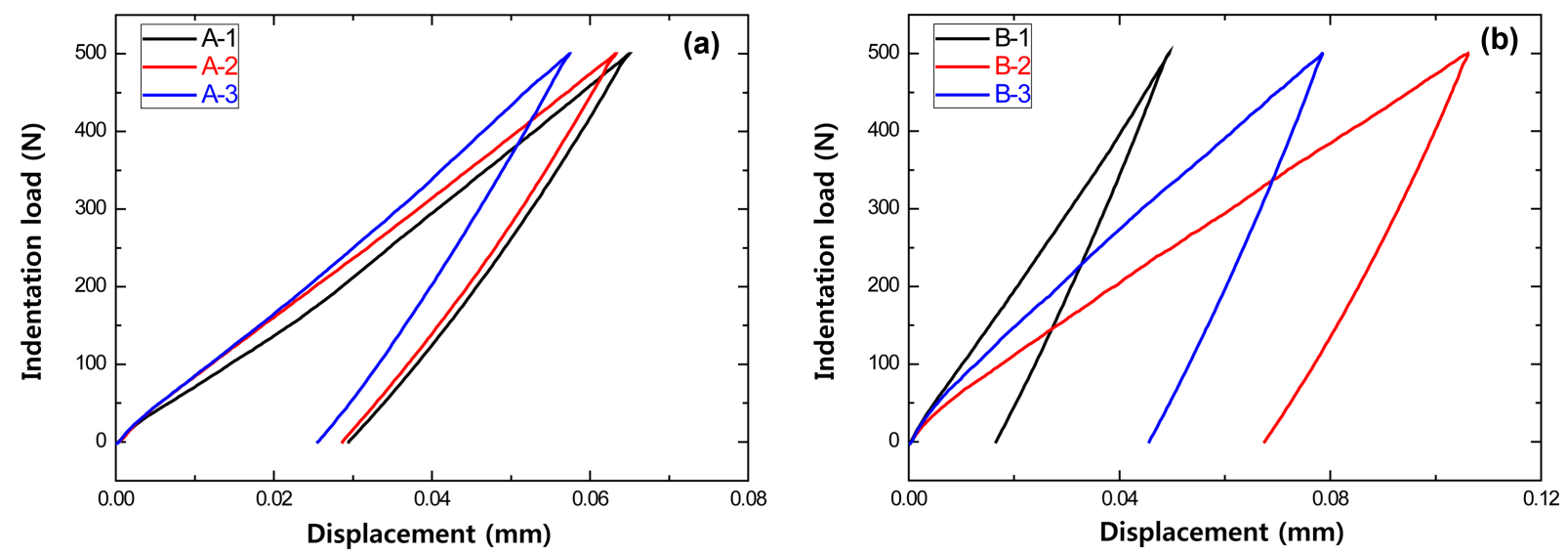

Fig. 3. Effect of carbon content on indentation load versus displacement of $\mathrm{MgO}-\mathrm{C}$ samples at room temperature using a WC ball $(r=6.36 \mathrm{~mm})$ at contact load $P=500 \mathrm{~N}$ : (a) $\mathrm{Al} / \mathrm{Al}_{2} \mathrm{O}_{3}$ antioxidant and (b) $\mathrm{Al} / \mathrm{Si} / \mathrm{Al}_{2} \mathrm{O}_{3}$ antioxidant.
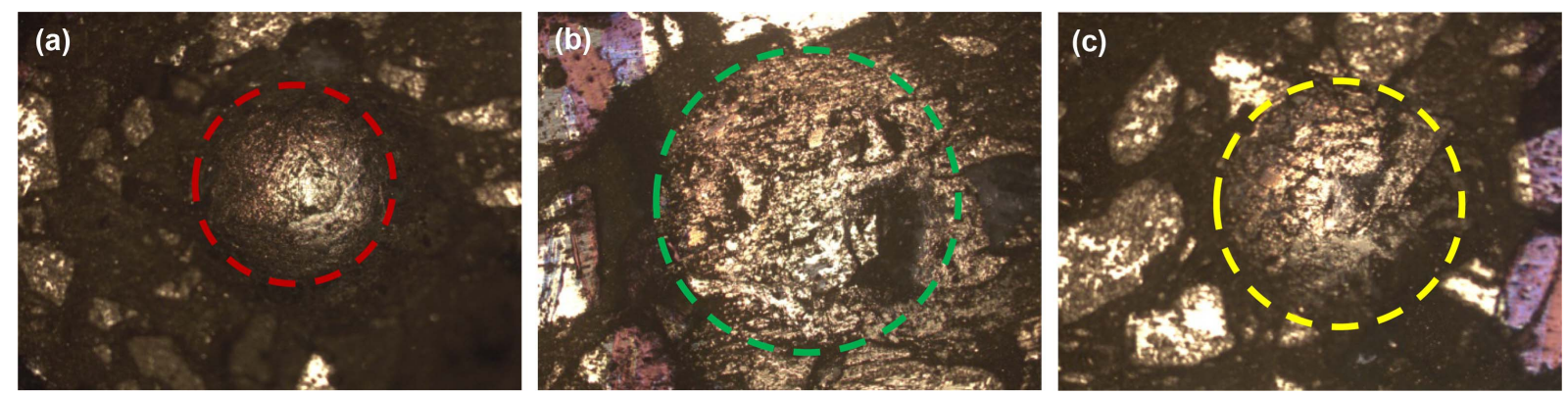

Fig. 4. Contact damage on surfaces of $\mathrm{MgO}-\mathrm{C}$ samples with $\mathrm{Al} / \mathrm{Si} / \mathrm{Al}_{2} \mathrm{O}_{3}$ antioxidant using a WC ball $(r=6.36 \mathrm{~mm})$ at contact load $P=500 \mathrm{~N}$ with different amounts of carbon: (a) $5 \mathrm{wt} \%$, (b) $17 \mathrm{wt} \%$, and (c) $14 \mathrm{wt} \%$. 


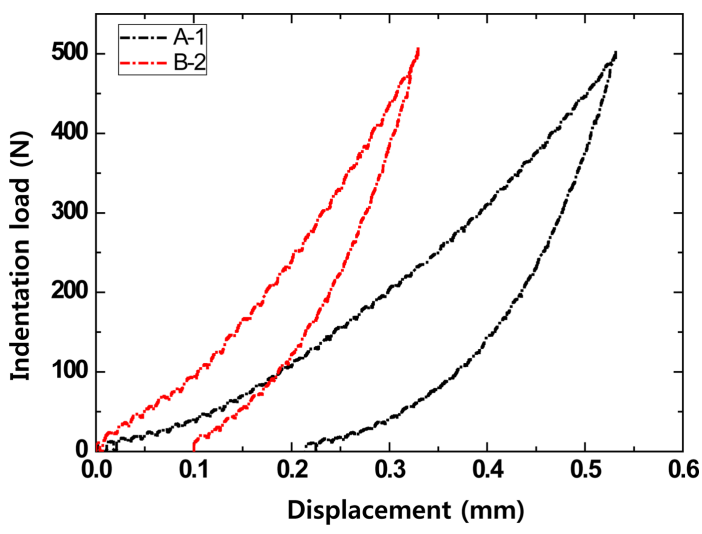

Fig. 5. Effect of antioxidant content on indentation load versus displacement of $\mathrm{MgO}-\mathrm{C}$ samples at room temperature using a WC ball $(r=6.36 \mathrm{~mm})$ at contact load $P$ $=500 \mathrm{~N}$.

$500 \mathrm{~N}$ and an indenter with $6.36 \mathrm{~mm}$ radius (Fig. 4).

Finally, when the surface (contact area) of the refractory, which is a composite material, was observed after indentation, the deformation was found to be small for the specimen with low carbon content, and the deformation was large for the specimen with high carbon content. As the carbon content increased, brittle fracture, which also appears in ceramics, was suppressed and deformation damage occurred (residual displacement). This result was due to the decreased modulus of elasticity of the refractory when the carbon content was increased. ${ }^{18)}$

Figure 5 shows the stress load-displacement behavior measured for specimens with varying antioxidant compositions in the $\mathrm{MgO}-\mathrm{C}$ refractory. The result for the $\mathrm{B}-1$ specimen containing both $\mathrm{Al}$ and $\mathrm{Si}$ showed that the deformation was relatively smaller compared to the A-1 specimens. Accordingly, it was determined that the major factor influencing the stress load-displacement was the antioxidant composition, rather than the carbon content. This result showed that the Hertzian indentation test offered clearer discernment in its results in comparison to the strength result of the conventional bending strength test method. These refractory experiment results regarding carbon con- tent in $\mathrm{MgO}-\mathrm{C}$ were in agreement with the results of the previously conducted Hertzian indentation testing. ${ }^{10)}$

\subsection{Indentation Characteristics According to the Indentation Temperature}

The $\mathrm{Al}$ antioxidant commonly used in this study improves strength as it turns to $\mathrm{Al}_{4} \mathrm{C}_{3}$ or other carbides from about $700^{\circ} \mathrm{C}$, and oxidation reaction occurs at high temperatures of $1000^{\circ} \mathrm{C}$ and above. As can be observed in Figs. 6 and 7, the deformation decreased in comparison to that of room temperature and then the deformation increased again when the indentation temperature increased to $1200^{\circ} \mathrm{C}$ and higher. This result was due to the metallic antioxidant added for antioxidant effect in the refractory (especially carbon); the antioxidant transitioned to $\mathrm{Al}_{2} \mathrm{O}_{3}$ at $1200^{\circ} \mathrm{C}$ and improved the mechanical properties. ${ }^{19)}$

The maximum and residual deformation difference was analyzed using the deformation according to temperature, to investigate the reaction of the metallic antioxidant contained in the refractory. The experiment was conducted at the actual temperature that the refractories are used, and the measurement results are shown in Fig. 7(b). As the temperature during indentation increased, the maximum and residual deformation showed a tendency to decrease up to $1200^{\circ} \mathrm{C}$ and a tendency to increase afterwards, which was in agreement with the indentation stress-displacement behavior shown in Fig. 7(a).

\subsection{Fracture Strength and Indentation Load-Dis- placement Behavior Comparison}

Compared to the bending strength test, which can only carry out one test for one specimen, the Hertzian indentation test method does not damage the material or need to be applied up to the critical load, so multiple tests are possible, allowing more and more diverse results. Also, unlike the bending strength test, which employs a specified standard, the Hertzian indentation test is not largely influenced by the specimen size. Thus, the load range for investigating the refractory indentation load-deformation behavior using the Hertzian indentation method was set to $500 \mathrm{~N}$, and the load-
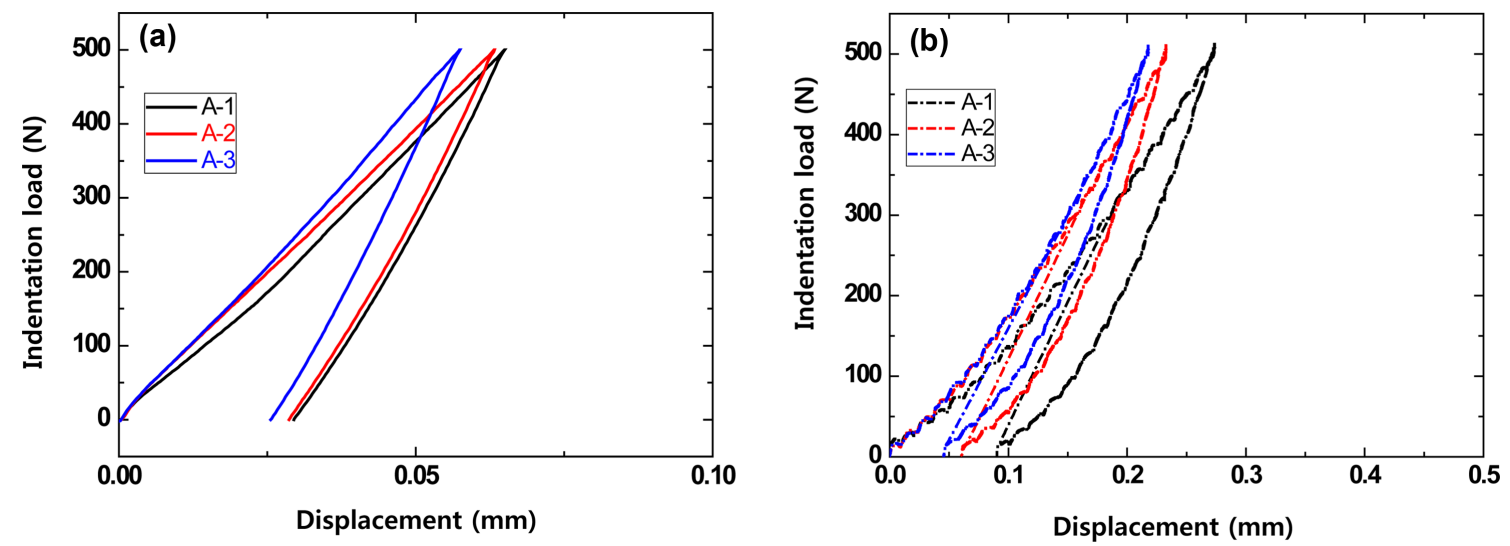

Fig. 6. Effect of indentation temperature on indentation load versus displacement of MgO-C samples using a WC ball $(r=6.36$ $\mathrm{mm}$ ) at contact load $P=500 \mathrm{~N}$ : (a) room temperature (b) $1500^{\circ} \mathrm{C}$. 

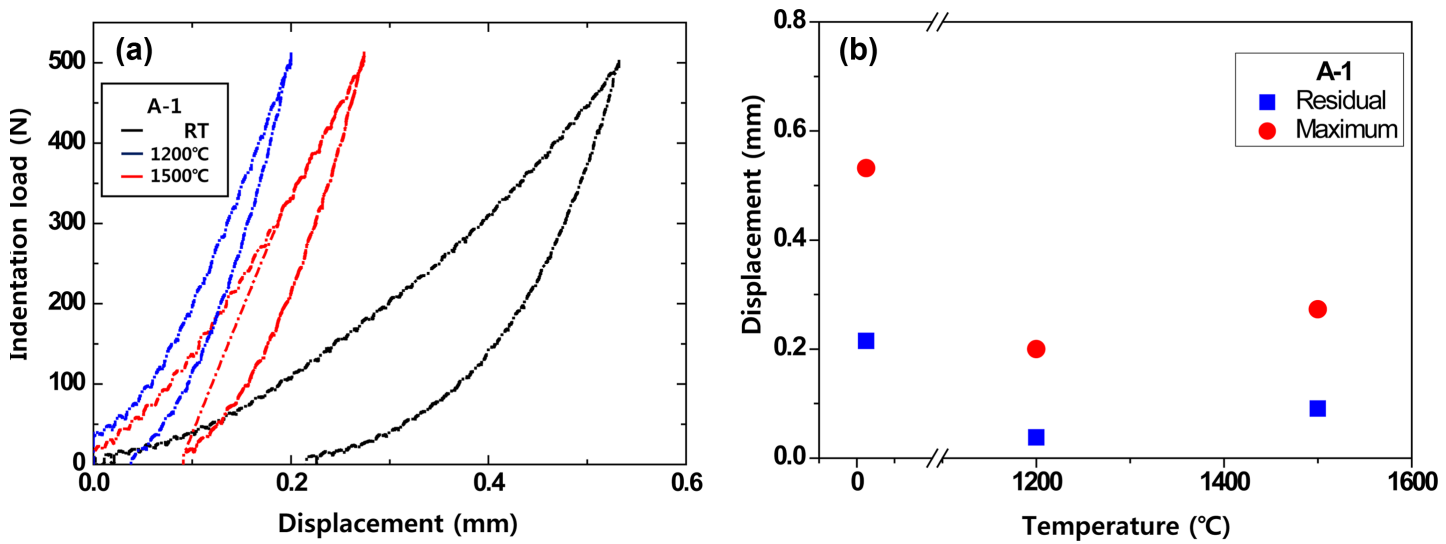

Fig. 7. Effect of indentation temperature on indentation load versus displacement of MgO-C sample using a WC ball $(r=6.36$ $\mathrm{mm}$ ) at contact load $P=500 \mathrm{~N}$ : (a) indentation load versus displacement at different indentation temperatures and (b) residual and maximum displacement.
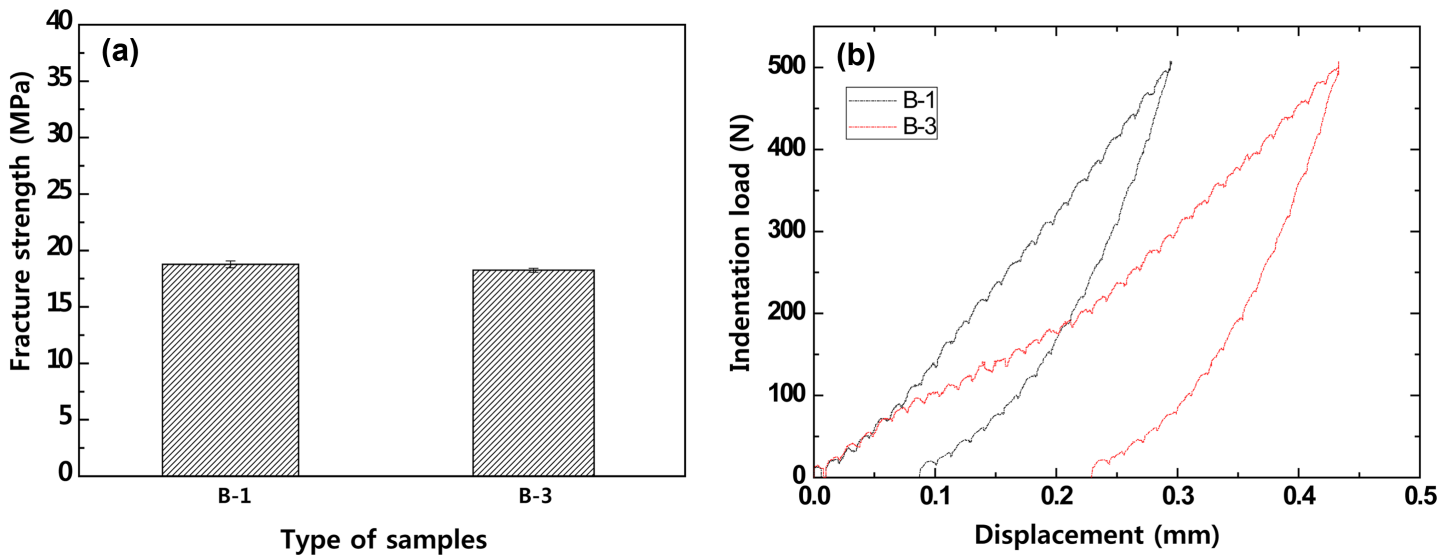

Fig. 8. Fracture strength and indentation load versus displacement of $\mathrm{MgO}-\mathrm{C}$ samples with $\mathrm{Al} / \mathrm{Si} / \mathrm{Al}_{2} \mathrm{O}_{3}$ antioxidant at $1500^{\circ} \mathrm{C}$ : (a) fracture strength and (b) indentation load versus displacement using a WC ball $(r=6.36 \mathrm{~mm})$ at contact load $P=$ $500 \mathrm{~N}$.

ing rate was set to $0.2 \mathrm{~mm} / \mathrm{min}$ for the measurements at high temperature, $1500^{\circ} \mathrm{C}$. Fig. 8 shows the results compared with the conventional bending strength property evaluation.

It was found that the B-2 specimen, which had greater carbon content compared to the B-1 specimen, deformed at small loads. Since this is affected by the binder content and manufacturing strength during fabrication, it was observed that the elastic modulus and strength were high when the carbon content decreased. ${ }^{10,15)}$ In contrast to this result, the conventional strength method result revealed that the strength of the B-1 specimen with a low carbon content was higher than that of the B-3 specimen but the difference was insignificant, so the effect of the carbon content could not be properly observed. Based on these results, it was determined that evaluating the properties of the refractory can be adequately carried out using the stress-deformation curve from the Hertzian indentation test method.

\subsection{Indentation Characteristics According to Inden-} tation Conditions

To investigate the impact fracture produced by refractory scraps, the effect of the drop speed has to be considered. This was reproduced by varying the indentation speed at $1500^{\circ} \mathrm{C}$ for the $\mathrm{B}$ type specimens, which had a large carbon content range from $5 \%$ to $17 \%$, to measure the maximum

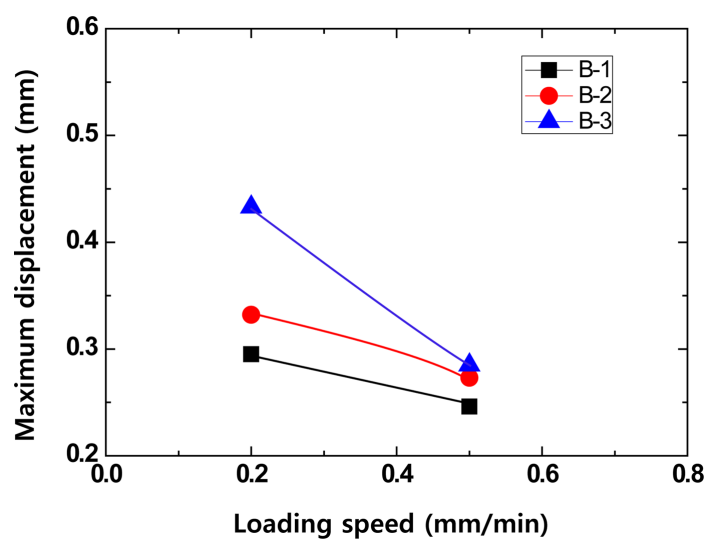

Fig. 9. Effect of crosshead speed at $1500^{\circ} \mathrm{C}$ on indentation load versus displacement of $\mathrm{MgO}-\mathrm{C}$ samples with $\mathrm{Al} /$ $\mathrm{Si} / \mathrm{Al}_{2} \mathrm{O}_{3}$ antioxidant using a WC ball $(r=6.36 \mathrm{~mm})$ at contact load $P=500$ N. 


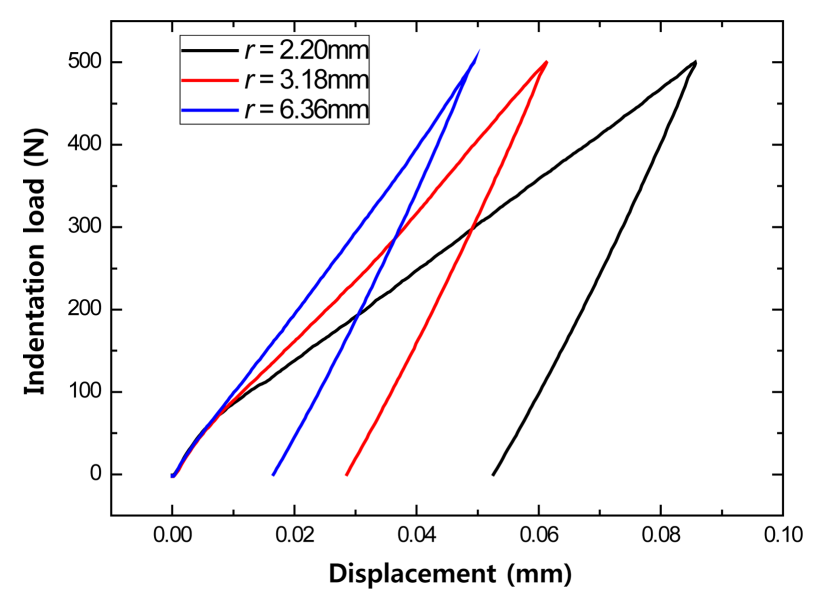

Fig. 10. Effect of ball radius on indentation load versus displacement of MgO-C sample with $5 \mathrm{wt} \%$ carbon content at contact load $\mathrm{P}=500 \mathrm{~N}$.

displacement, which is shown in Fig. 9. When the indentation speed was low, the load during indentation was transferred to the refractory in its entirety, but when the indentation speed increased, the deformation tended to decrease. When the indentation speed increased, the impact energy dissipated so that the load was not transferred to the test specimen in its entirety.

The Hertzian indentation test was conducted with various indenter sizes to investigate the effect of the curvature radius of the scrap that comes into contact with the refractory. However, the refractory is composed of various compositions and particle sizes, which means the refractory does not have a uniform structure, thus, the displacement according to the load was measured using indenters of different sizes. Fig. 10 shows the measurement results for the $\mathrm{MgO}-\mathrm{C}$ refractory with $5 \%$ carbon content using a constant load, indentation speed of $0.2 \mathrm{~mm} / \mathrm{min}$, and indenters of 2.20, 3.18, and $6.36 \mathrm{~mm}$ sizes. As the indenter size increased, the contact area increased, reducing the stress on the refractory, so a relatively large indenter resulted in a smaller indentation displacement for a constant load.

However, because the refractory does not have a uniform microstructure, varying slopes were obtained depending on the indenter size, so the elastic modulus varied.

\subsection{Indentation Characteristics According to the Repetition Number}

The Hertzian indentation fatigue test was conducted to predict the lifespan due to the drop impact of scraps on the refractory. To obtain the fatigue characteristics, experiments were carried out with specimens having $17 \%$ carbon content, for a constant indentation load of $500 \mathrm{~N}$ and temperature of $1500^{\circ} \mathrm{C}$, the level at which refractories actually operate. Fig. 11 shows the experimental results. It was found that the damage size tended to increase gradually along with the contact fatigue, and that the damage size saturated above a certain repetition number. Additionally, it is thought that the damage size will saturate for small

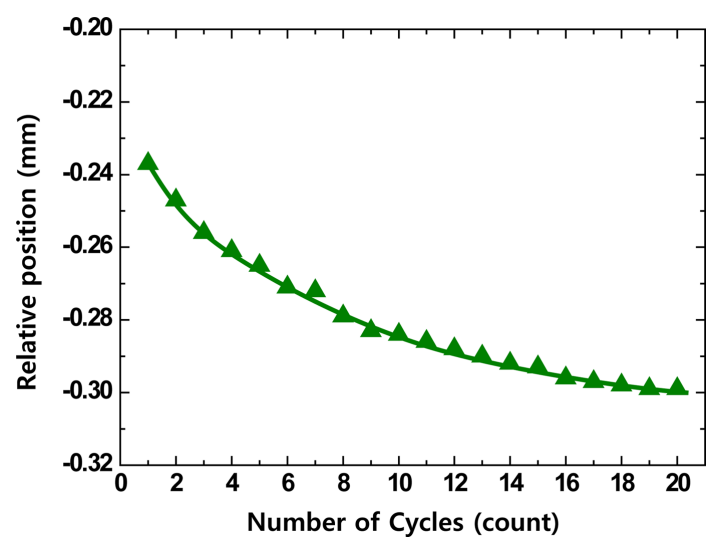

Fig. 11. Contact fatigue behavior at $1500^{\circ} \mathrm{C}$ as a function of number of cycles for $17 \mathrm{wt} \% \mathrm{MgO}-\mathrm{C}$ sample using a WC ball $(r=6.36 \mathrm{~mm})$ at contact load $P=500 \mathrm{~N}$.

repetition numbers when the carbon content is low. The importance of the initial damage was observed, as the variation range decreased above a certain repetition number. This result was similar to the observed amount of erosion related to the frequent use of the charging pad lining of $\mathrm{MgO}-\mathrm{C}$ refractory in converter, where scrap drop impacts occur on actual converters.

\section{Conclusions}

In this study, the Hertzian indentation test was used to investigate the damage mechanism, and as the impact fracture evaluation method, for scrap drops during converter operation. Stress load-displacement and damage behaviors were evaluated based on the carbon content and antioxidant content and composition, using the Hertzian indentation test. It was found that the maximum and residual deformation of the refractory increased as the carbon content increased, at room and high temperatures, and the elastic modulus decreased. Also, tests revealed tendencies of decreasing maximum and residual deformation as the indenter size increased, and decreasing deformation for high loading rates. However, the deformation increased according to the loading rate. Using these results, the conventional refractory characteristic evaluation method was used to predict property changes according to difficult composition changes as well as observe the refractory damage behavior. Because the impact energy of scrap drops on refractories can vary depending on the scrap shape, including a spherical shape, the Hertzian indentation test is expected to be useful in the prediction of refractory lifetime due to scrap drops. The findings of this study can be utilized to identify the impact fracture mechanism, based on scrap charging in actual converter operation.

\section{Acknowledgments}

This work was supported by a National Research Foundation of Korea (NRF) grant funded by the Korean government 
(MSIP) (NRF-2016R1D1A3B03934054 and 2018R1A5A6075959).

\section{REFERENCES}

1. S. Zhang, N. K. Marriott, and W. E. Lee, "Thermochemistry and Microstructure of MgO-C Refractories Containing Varous Antioxidanats," J. Eur. Ceram. Soc., 21 [8] 103747 (2001).

2. K. Horii, N. Tsutsui, Y. Kitano, and T. Kato, "Processing and Reusing Technologies for Steelmaking Slag," Nippon Steel Tech. Rep., 104 123-29 (2013).

3. H. Harmuth, "Stability of Crack Propagation Associated with Fracture Energy Determined by Wedge Splitting Specimen," Theor. Appl. Fract. Mech., 23 [1] 103-8 (1995).

4. M. Bag, S. Adak, and R. Sarkar, "Study on Low Carbon Containing MgO-C Refractory: Use of Nano Carbon," Ceram. Int., 38 [3] 2339-46 (2012).

5. T. Zhu, Y. Li, S. Jin, S. Sang, Q Wang, L. Zhao, Y. Li, and S. Li, "Microstructure and Mechanical Properties of MgOC Refractories Containing Expansion Graphite," Ceram. Int., 39 [4] 4529-37 (2013).

6. G. Wei, B. Zhu, X. Li, and Z. Ma, "Microstructure and Mechanical Properties of Low Carbon MgO-C Refractories Bonded by an Fe Nanosheet-Modified Phenol Resin," Ceram. Int., 41 [1] 1553-66 (2014).

7. H. Harmuth, K. Rieder, M. Krobath, and E. Tschegg, "Investigation of the Nonlinear Fracture Behaviour of Ordinary Ceramic Refractory Materials," Mater. Sci. Eng., A, 214 [1] 53-61 (1996).

8. B. Hashemi, Z. A. Nemati, and M. A. Faghihi-Sani, "Effects of Resin and Graphite Content on Density and Oxidation Behavior of MgO-C Refractory Bricks," Ceram. Int., 32 [3] 313-19 (2006).

9. S. Mauthoor, R. Mohee, and P. Kowlesser, "An Assessment on the Recycling Opportunities of Wastes Emanating from Scrap Metal Processing in Mauritius," Waste
Manage., 34 [10] 1800-5 (2014).

10. K. S. Lee, G. H. Cho, Y. G. Jung, and Y. K. Byeun, "Effect of Carbon Content on the Mechanical behavior of MgO-C Refractories Characterized by Hertzain Indentation," Ceram. Int., 42 [1] 9955-62 (2016).

11. F. Guiberteau, N. P. Padture, H. Cai, and B. R. Lawn, "Indentation Fatigue: A Simple Cyclic Hertzian Test for Measuring Damage Accumulation in Polycrystalline Ceramics," Philos. Mag. A, 68 1003-16 (1993).

12. H. Hertz, Verhandlungen des Verins Zur Bef orderung des Gewerbe Fleisses; Vol. 61, p. 410, Macmillan, London, 1882.

13. B. R. Lawn, Fracture of Brittle Solids; Vol. 1, pp. 249-306, Cambridge University Press, Cambridge, 1993.

14. B. R. Lawn, "Indentation of Ceramics with Spheres: A Century after Hertz," J. Am. Ceram. Soc., 81 [8] 1977-94 (1998).

15. H. Cai, M. A. Stevens Kalceff, and B. R. Lawn, "Deformation and Fracture of Mica Containing Glass-Ceramics in Hertzian Contacts," J. Mater. Res., 9 [3] 762-70 (1994).

16. H. Zhang, Z. Z Fang, and Q. Lu, "Characterization of a Bilayer WC-Co Hardmetal Using Herzian Indentation Technique," Int. J. Refract. Met. Hard Mater., 27 [2] 31722 (2009).

17. B. R. Lawn, S. K. Lee, I. M. Peterson, and S. Wuttiphan, "Model of Strength Degradation from Hertzian Contact Damage in Tough Ceramics," J. Am. Ceram. Soc., 81 [6] 1509-20 (1998).

18. K. Zeng, K. Breder, D. J. Rowcliffe, and C. Herrstrom, "Elastic Modulus Determined by Hertzian Indentation," J. Mater. Sci. Technol., 27 [14] 3789-92 (1992).

19. S. H. Cheon, H. S. Kong, and B. S. Jun., "Kinetics of Oxidation, and Effects of TiC Oxidation Resistance in $\mathrm{MgO}$ Carbon Refractory," J. Korean Ceram. Soc., 41 [9] 657-62 (2004). 